\title{
A method for establishing bird conservation value at a landscape level
}

\author{
LORENZO FORNASARI, ELISABETTA DE CARLI, LUCIANA BOTTONI \\ and RENATO MASSA
}

\section{Summary}

To produce conservation indices from bird community data, with the aim of identifying and comparing areas of regional conservation concern, we selected bird community samples randomly over a large study area, without including habitat features a priori in the sampling procedure. Subsequently, we subjected the samples to a cluster analysis to identify a posteriori bird communities to be indexed together with their associated habitat and distribution/abundance on a regional scale. We identified 15 bird community types and were able to characterize each of them by a community conservation index (CCI) taking into account three different components of rarity: habitat selectivity, geographical distribution, and abundance. A cluster of four communities was associated with lowland farmland and woodland; another cluster of five was found at higher average altitudes and degree of urbanization; a third one of six showed a montane distribution. This third cluster showed much higher $\mathrm{CCI}$ values in comparison with the first two suggesting that the index here proposed is very sensitive to a high community selectivity and a restricted distriblution/abundance.

\section{Introduction}

Recently, emphasis in wildlife conservation has been placed "on proactive conservation of species assemblages before severe population declines are evident, rather than on reactive restoration of individual species that have suffered major population losses". According to Petit et al. (1995), this means that "to meet the future goals for maintenance of ecosystem integrity ...., implementation of management practices at a local scale must be viewed in the broader context of ecological processes occurring at landscape and regional levels (Noss 1983; Probst and Crow 1991; Franklin 1993)".

Because of their conspicuousness, ubiquity and ecological diversity, birds have repeatedly been used as indicators of broad environmental quality in extensive land use planning (for example Graber and Graber 1976; Svensson 1977; van der Ploeg and Vlijm 1978; Blana 1980; Haila 1985; Solonen 1985; Fornasari and Massa 1990). Although bird community characteristics may or may not be linked to overall biodiversity (Prendergast et al. 1993), the ornithological evaluation of a landscape (see Fuller and Langslow 1986) is certainly important at least for birds of conservation concern. Birds have been used in identifying areas of major interest in conservation programmes (ICBP 1992), sometimes by trying to estimate conservation values of bird communities 
and habitats by means of cumulative indices (Jarvinen 1982; Jarvinen and Rauta 1982; Haila 1985).

Even if measures of bird species diversity or of species richness have often been used in evaluation systems, most diversity indices have shown both biological and statistical problems (for example May 1976; Southwood 1978; Routledge 1980; James and Rathbun 1981). The widespread use of such indices on a wide variety of spatial scales has been subjected to much criticism, mainly because they largely depend on the size of the sample (Wiens et al. 1986; Wiens 1989a). Moreover "combined indices - constructed with data on different species collected from different places - are suspect because they usually emphasize exceptional rather than ordinary habitat type" (Haila 1985). For these and other reasons, Jarvinen (1985) argued that "both technical and ecological arguments lead to the conclusion that conservation indices attempting a generally valid assessment of the conservation value of different ornithological sites are and probably always will be inadequate". This is so because "ornithological expertise is used to rank different areas and the indices are based on a more or less ad hoc method that yields 'reasonable' results for the problem at hand but not necessarily in other contexts".

In addition, conservation indices are generally based on data collected by means of traditional a priori sampling approaches, on the implicit assumption that birds do select habitat types readily identifiable by humans. In fact, most bird community studies are conducted implying direct human judgement of bird-habitat relationships to relate single or multiple habitat features with bird presence and or density (e.g. Rotenberry and Wiens 1978; Grzybowsky 1982). However, indices will certainly be affected by bird dispersion and this will, in turn, be affected by scale. Differences in scale are critically important "for they influence the questions that can be addressed, the procedures followed, the observations obtained and how the results are interpreted" (Wiens 1989b).

All these observations can be summarized in two key problems: (1) the misidentification of community "borders" may overestimate or underestimate the usual community parameters (i.e. richness or diversity); and (2) some simple bird communities may be of higher conservation concern than more rich or diverse bird communities, on the basis of some other attribute like typicalness or representativeness (see Margules and Usher 1981), or for their original contribution to regional or global biodiversity. Rich or diverse bird communities may include a wide majority of trivial species, while more simple bird communities may comprise high rates of rare and localized species. The local conservation of a rich and diverse bird community may not affect global biodiversity at all, while this can be influenced by the conservation of a less rich and less diverse bird community that is rare or rarefied, localized from a geographical or an ecological point of view.

The aim of this work was to find an objective way to compare different bird communities identified in a large area, taking into account their biological attributes related to the concept of rarity. These parameters have been measured at the same level of sampling. The result of the procedure further described has been compared with a "traditional" species by species evaluation performed on the basis of the study of birds of conservation concern by Tucker and Heath (1994). 
To identify discrete community types to be indexed on an objective basis, the use of cluster analysis appears appropriate. According to Fuller and Langslow (1986) "multivariate techniques of analysis may help in . . . classifying the bird communities". In the words of Gauch (1982): "the application of multivariate analysis to community ecology is natural, routine, and fruitful". The bird species assemblages obtained by means of this approach are reminiscent of the concept of "association" largely used by the field botanists to identify constant plant communities without reference to external variables (Lebreton and Yoccoz 1987). An example of such an approach is that of Opdam and Retel Helmrich (1984) who classified Dutch heathland bird communities into eight species-rich and five species-poor types. To identify such bird assemblages and produce conservation indices from these data, we chose bird samples randomly over a large study area and - although we did collect habitat data - we did not include such data a priori in the sampling procedure.

Finally, we used three different rarity parameters of the bird assemblage obtained (geographical distribution, abundance, selectivity) to define and calculate a Community Conservation Index (CCI). In the present paper, we have estimated such conservation values within a very large area, the whole of Lombardy. This is an administrative region of Northern Italy covering $23,842 \mathrm{~km}^{2}$ between the Southern Alps, Po valley and Northern Appennines and showing a high landscape diversity with scarcely populated mountain areas and an extremely densely settled alluvial lowland.

\section{Study area and methods}

\section{Data collection}

The bird data analysed here were originally collected in a pilot survey aimed to produce a quantitative breeding bird atlas of Lombardy. The sampling was planned so as to combine this atlas work with a bird monitoring project, including the collection of information on bird habitat selectivity (for further explanation see Massa 1993, Fornasari et al. 1995).

To prepare the sampling design we divided the region in 40 homogeneous landscape districts, each of them composed of eight primary census units. These units consist of $10 \times 10 \mathrm{~km}$ maps, produced by the national army geographic institute (Istituto Geografico Militare Italiano, IGMI). Districts were drawn by choosing contiguous maps, on the basis of similarities in altitude, relative presence of farmland, woodland (broad-leaved or coniferous), lakes, large rivers, urban areas and other kind of habitats. Extremely useful at this stage were the habitat data collected during the winter atlas work (Massa et al. 1990). A total of 10 gross landscape types was identified (Figure 1).

The programme foresees eight different surveys, directed to cover 40 $10 \times 10 \mathrm{~km}$ maps (primary units) each year. The location of these units is decided by extracting a number between 1 and 8 and then moving from left to right and from the top to the bottom within each homogeneous district.

The coverage of each primary unit usually has to be done in a single visit, between May 1oth and June 2oth, by means of randomly selected secondary census units (Massa and Fedrigo 1989). Secondary units consist of 10 minutes 


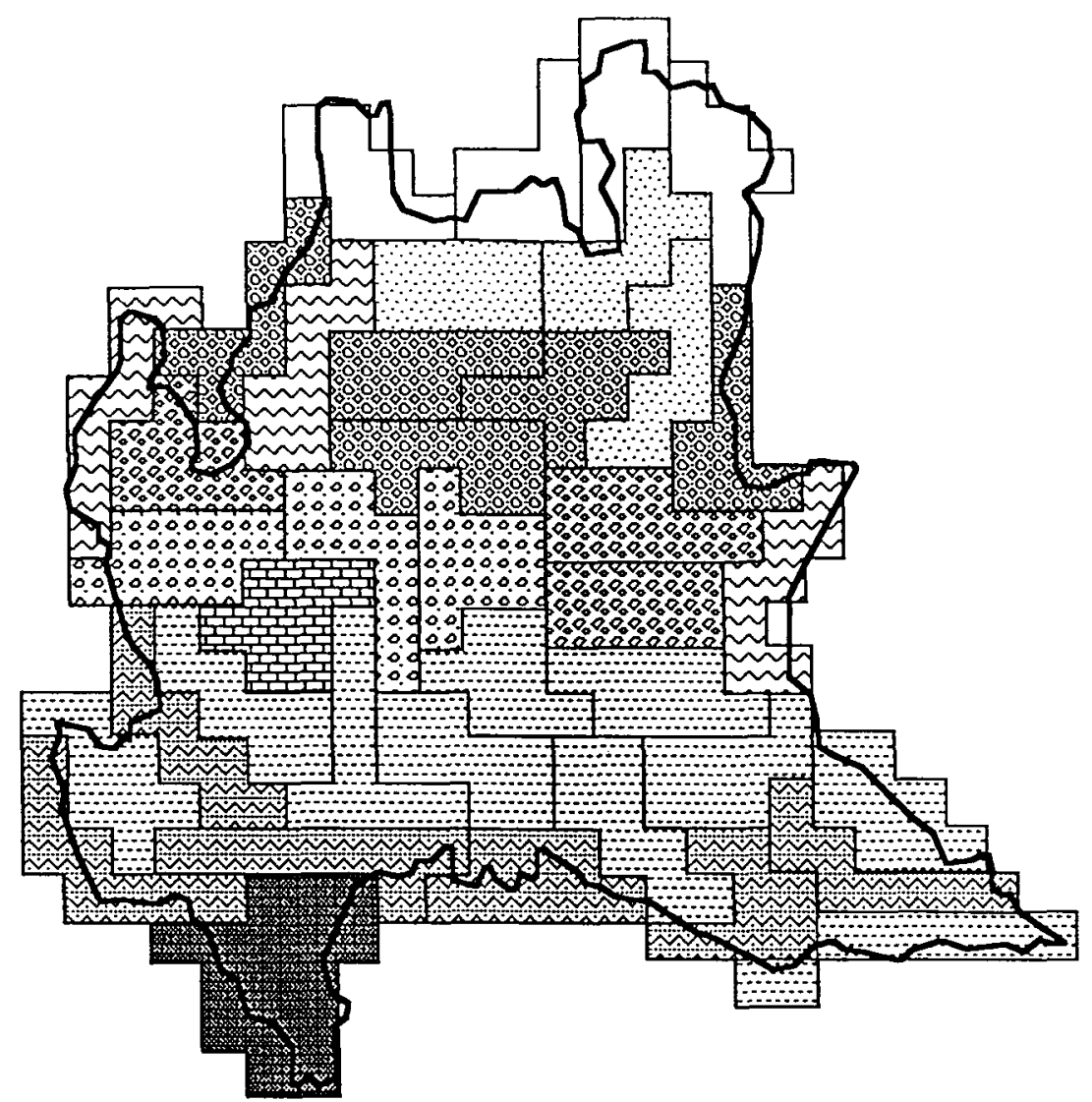

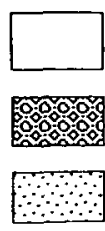

Alps (4 districts)

Prealps (5 districts)

Alpine valleys(3 districts)

Eman

Coasts and lakes (3 districts)

Hills (3 districts)
Lowlands healthland (3 districts)

Greater Milan (1 districts)

Lowlands farmland ( 10 districts)

Large Rivers (6 districts)

Appennines(2 districts)

Figure 1. Distribution of the 40 homogeneous Lombardy districts, grouped in 10 main categories on the basis of general landscape features.

unlimited distance point counts, performed within $1 \times 1 \mathrm{~km}$ squares which are randomly located whithin each $10 \times 10 \mathrm{~km}$ map (Blondel et al. 1981; Massa and Fedrigo, 1989). The actual point count is finally performed at the most convenient location, usually near a road or a track, in a well-vegetated site. 
Montane squares inaccessible by car are visited on foot; however, in case of entirely inaccessible squares, these are replaced by new randomly selected squares. Such a substitution may introduce some bias on scarce species associated with inaccessible squares, but the randomized design avoids significant biases at the community level (just because the scarce species have a low quantitative importance). Moreover, previous winter atlas work (Fornasari et al. 1992) showed that such a method is very powerful for drawing general patterns.

At each site birds are recorded, if possible with sex, number and activities (e.g. singing males, family parties). Data are then transformed into numbers of pairs, according to Blondel et al. (1981). We also record altitude, exposure, habitat and environmental variables, choosing from 56 codes pertaining to eight main categories (forest, small woods, heath, farmland, rocks, lakes/rivers, factories and urban areas). The main categories are each scored by $5 \%$. An openness index and an urbanization index, both from o to 5 , are also scored (Fornasari and Massa 1990).

During the preparatory survey conducted according to this method in 1992 we covered $4010 \times 10 \mathrm{~km}$ maps, performed 417 point counts of 10 minutes and detected a total of 24,347 birds, comprising 128 species (Fornasari et al. 1995). The coverage of each map was usually achieved in a single day by means of 10 point counts.

\section{Data analysis and index calculation}

The bird data collected were analysed to identify the different bird assemblages of the region, that we considered as bird community types (sensu MacArthur 1971). We first converted our point count data into a sample/species matrix. This was subjected to a cluster analysis using the Pearson product moment correlation coefficient (Hayek, 1994) as a measure of similarity distance among all the bird lists. These were then subjected to the complete linkage procedure (Figure 2) to build up a correlation tree (Lance and Williams 1967; Gauch 1982). Separate clusters - in our case representing 15 different community types - are generated by point count bird lists clustering above a correlation value equal to zero. Bird lists that are positively related share at least some species with a similar quantitative importance, so that they cluster together; negatively related bird lists share few species with different quantitative importance, so that they shift into different clusters.

The above defined bird communities represent the basis on which to define and calculate our Community Conservation Index (CCI). We took into account three different components of rarity (Fiedler and Ahouse 1992), that is community geographical distribution, community abundance and community total species selectivity. The latter is directly proportional to rarity and therefore appears in the numerator; the first two, being partially related (Gaston and Lawton 1990; Novotn 1991) and both inversely proportional to rarity, are combined in the denominator as a geometrical mean. Therefore, $\mathrm{CCI}$ may be defined as:

$$
\mathrm{CCI}=\mathrm{TSS} \vee(\mathrm{A} \times \mathrm{D})
$$




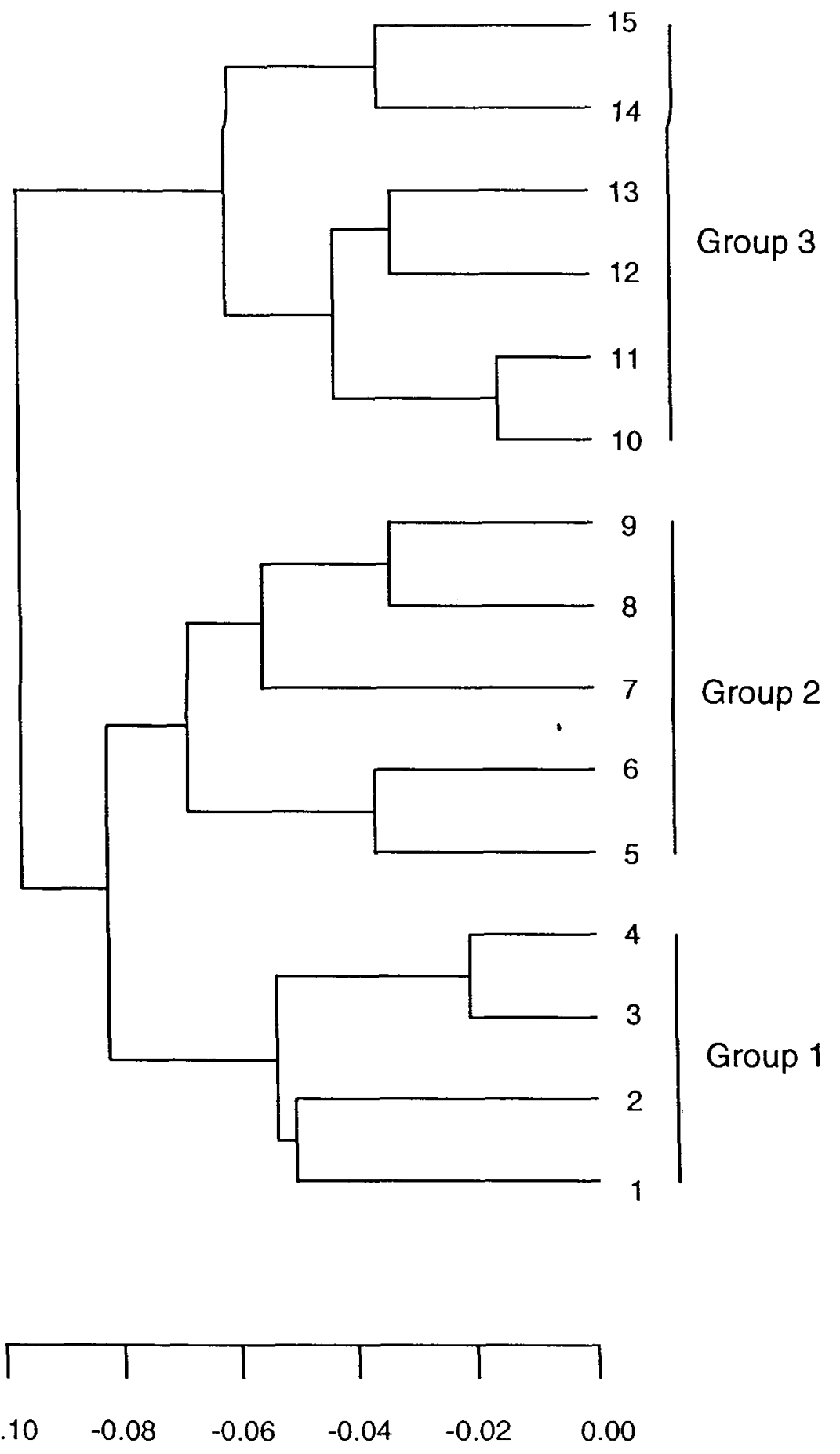

Figure 2. Cluster tree of the 15 community types identified and their correlation values. 
where TSS (total species selectivity) is the summation of the percentage values (dominances) within a given community for all the species significantly selective for that community. "Significantly selective species" are those for which the ratio between species abundance in that given community and average species abundance in the rest of the region is significantly higher than $1\left(P<0.05 ; \chi^{2}\right.$ test). These species are found more often in the given community - and in the habitat associated with it - rather than in the average space of the entire region; this difference can easily be shown by the dominance ratio between the percentage values within the given community and within the whole of the region. A (abundance) is the percentage of point counts pertaining to a given community. D (geographical distribution) is the percentage of districts where a given community is present.

Abundance and geographical distribution give complementary information (e.g. Fiedler and Ahouse, 1992): a given community type may be found (a) in few point count stations, obviously related to a small geographic area (rare communities); (b) in several point count stations within a restricted geographic area (concentrated communities); (c) in few point count stations scattered on a wide geographic area (rarefied communities); or (d) in several point count stations scattered on a wide geographic area (widespread communities).

\section{Evaluation of the "rarity based" community index}

In order to compare $\mathrm{CCI}$ with other possible indices that might be obtained by considering the conservation status at the level of species rather than of community, we also defined and calculated a European Conservation Index (ECI) based on the official status (Tucker and Heath 1994) of the bird species listed in each of our 15 communities. For the purpose of this calculation, we only scored, in each community, species represented in the SPEC categories 1-4 of Tucker and Heath (1994) - that is we only scored species of some conservation concern - and discarded all others. We scored 1 for each species placed in category 4 (favourable conservation status, global population concentrated in Europe), 2 for category 3 (unfavourable conservation status but not concentrated in Europe), 4 for category 2 (unfavourable conservation status, concentrated in Europe) and 8 for category 1 (globally threatened, conservation dependent).

The CCI was also compared with the most used community indices, i.e. diversity of Shannon and Weaver (MacArthur and MacArthur 1961) and the "diversity based" equitability (Pielou 1969). Shannon and Weaver diversity is defined as $\mathrm{H}=-\Sigma\left(p_{i} \ln p_{i}\right)$, where $p_{i}$ is the percentage represented by the $i$ th species within the given community, while equitability is defined as $J=H / l n S$, where $S$ is the total number of species within the given community.

\section{Results}

Trend of $\mathrm{CCI}$

By cutting the correlation tree at the correlation value of zero (no correlation among clusters), we identified 15 bird community types. These cluster into three main groups: group 3 with six community types, then groups 2 and 1 


\section{Habitat types}

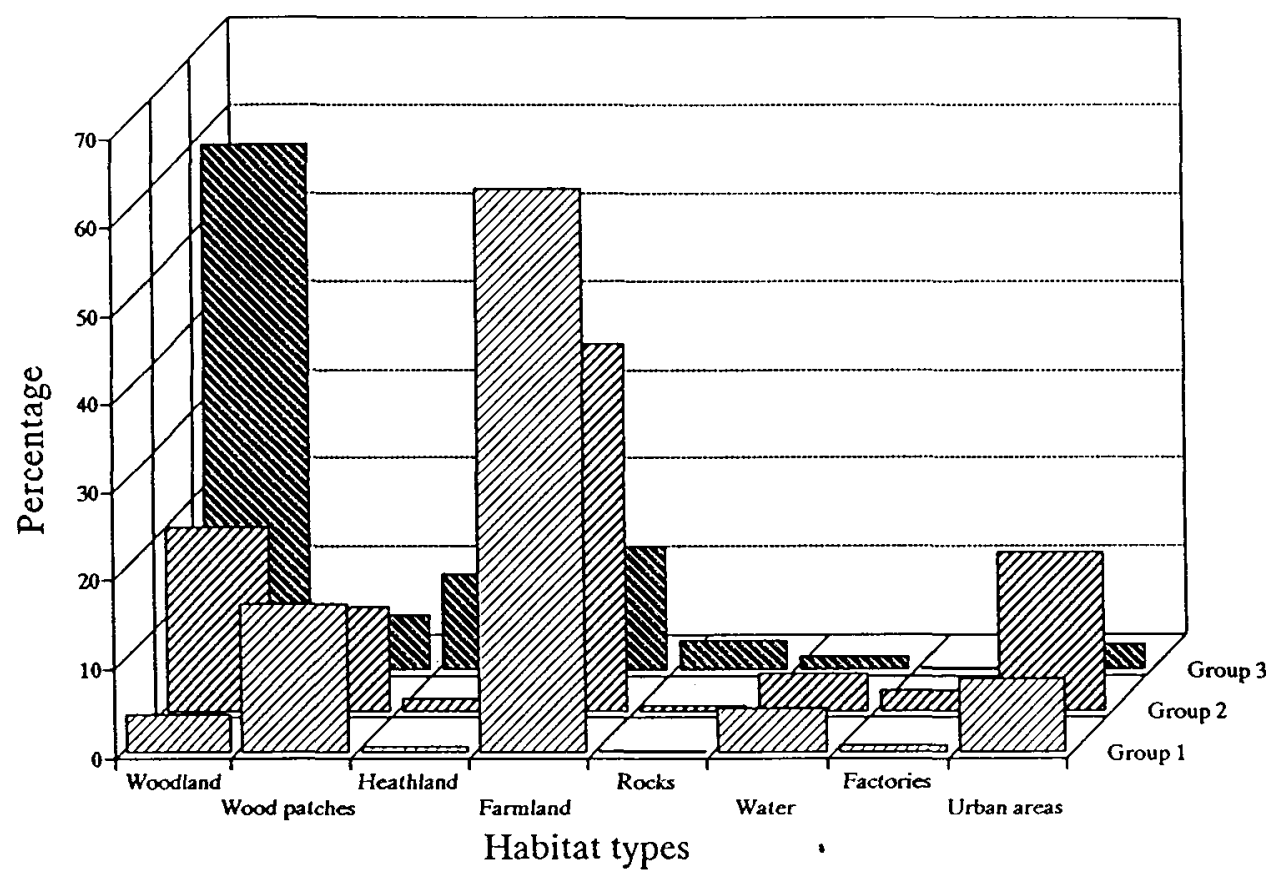

Figure 3. Average habitat characteristics for the three main community groups. Habitat percentages were estimated within a fixed radius of $500 \mathrm{~m}$ from the point count stations.

respectively with five and four community types (Figure 2). Among these, group 1 is associated with the lowland (farmland and river habitats); group 2 shows its highest densities at higher average altitudes and at a higher degree of urbanization; group 3 shows a montane distribution. A summary of the characteristics of each community type, with positive selective species (dominance ratio indicated) is shown in Appendix 1. The corresponding habitat characteristics are also summarized in Figure 3.

Figure 4 shows the three rarity components of CCI for the 15 communities identified, where rarest communities are located near the origin (low values of distribution and abundance and high values of selectivity, that is highest $\mathrm{CCI}$ ). This position is occupied mainly by montane communities; the rarest community (community 15 ) is at the highest altitude level, being always found over $2200 \mathrm{~m}$ above sea level (see Appendix 1). The less rare montane communities are characterized by a relative low value of selectivity; for example community 6 shares several selective species with some other extensive woodland communities (of both group 2 and group 3). Generally, community types of group 2 (related to rural and urban habitats) are found at homogeneous low levels of TSS, while community types of group 1 (related to lowland habitats) show together low TSS and high distribution and abundance.values. Within Group 1, the only exception is community 3, in which most of the selective species (and particularly the four herons indicated in Appendix 1) 


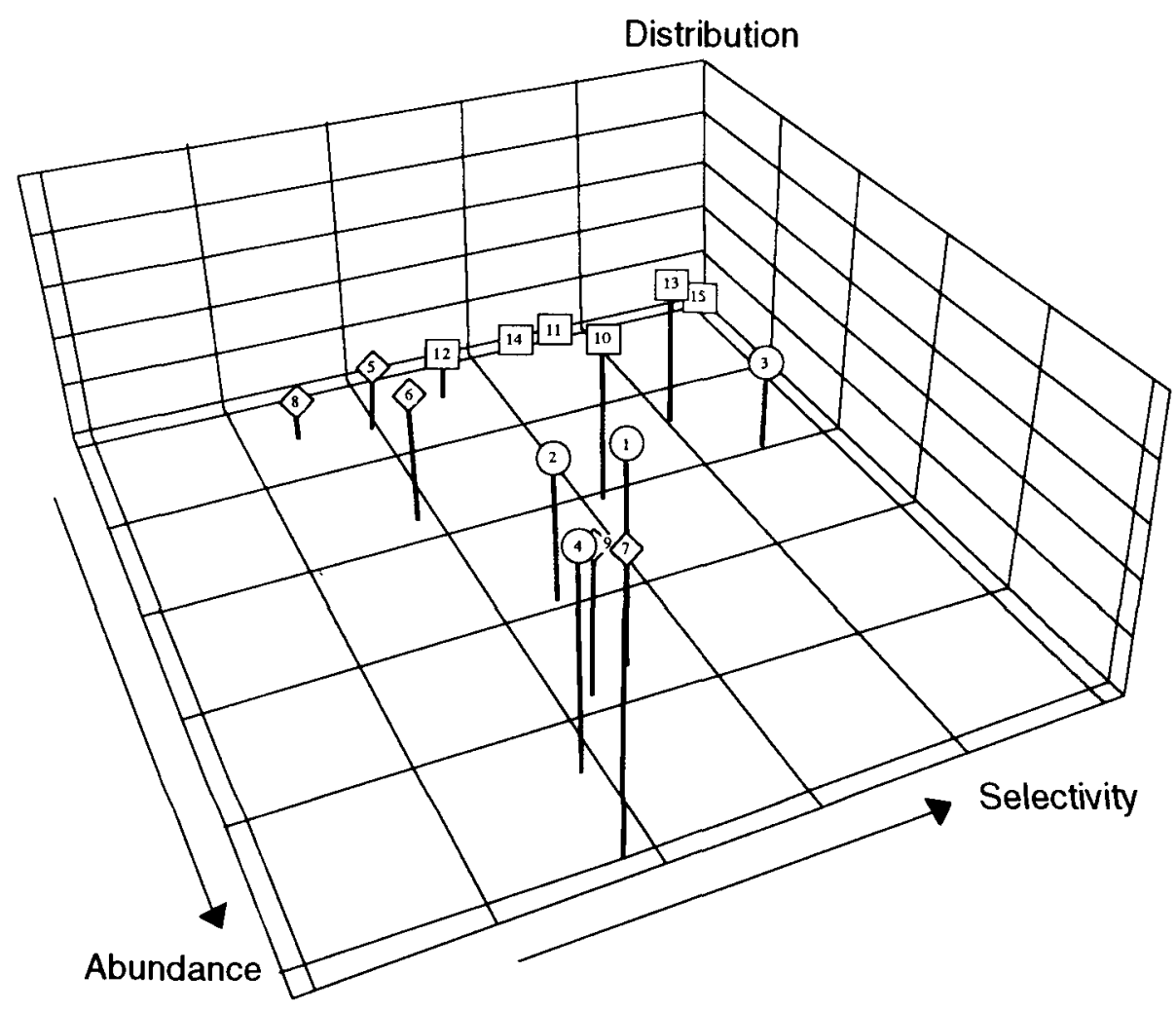

Figure 4. Position of the 15 bird communities identified by the three rarity components: geographical distribution, abundance and selectivity. All scales are in percentages (see text for further explanations). Circles, group 1 (lowland communities); diamonds, group 2 (rural and urban communities); squares, group 3 (montane communities).

clearly explain the relation with the main rivers of the region, localized in the same sectors occupied.

Selectivity values generally parallel those of CCI (Table 1) except in the case of high values of abundance and distribution. The three components show a similar influence on CCI values, being highly correlated, respectively, in a positive or in a negative way (TSS: $r=0.69, P<0.01$; A: $r=-0.69, P<0.01$; D: $r=-0.71, P<0.01)$.

\section{Comparison with other indices}

We found a negative correlation $(r=-0.70 ; P<0.01)$ between the two series of CCI and ECI values for the 15 communities (Table 1 ). The ECI was found positively correlated with geographical distribution $(r=0.95 ; P<0.01)$ and abundance $(r=0.98 ; P<0.01)$.

Shannon diversity appeared unrelated with ECI $(r=0.58 ; P>0.05)$ and negatively correlated with CCI $(r=-0.90 ; P<0.01)$; conversely, equitability was slightly negatively correlated with ECI $(r=-0.58 ; P<0.05)$ and positively correlated with CCI $(r=0.49 ; P<0.05)$. Values are listed in Table 1 . 
Table 1. Values of community conservation index (CCI) and other measured parameters for the 15 community types (see text for further explanations).

\begin{tabular}{lrrrrrrr}
\hline Community & TSS & Abundance & Distribution & CCI & H & J & ECI \\
\hline 1 & 50.2 & 12.8 & 50.0 & 2.0 & 3.19 & 0.77 & 2.88 \\
2 & 47.7 & 8.4 & 40.0 & 2.6 & 2.95 & 0.74 & 2.10 \\
3 & 90.4 & 5.1 & 30.0 & 7.3 & 2.80 & 0.73 & 1.08 \\
4 & 37.4 & 12.5 & 62.5 & 1.3 & 2.68 & 0.68 & 2.82 \\
5 & 59.2 & 3.6 & 17.5 & 7.4 & 2.97 & 0.81 & 0.66 \\
6 & 33.2 & 7.5 & 45.0 & 1.8 & 3.29 & 0.77 & 1.64 \\
7 & 26.3 & 16.1 & 65.0 & 0.8 & 3.04 & 0.73 & 3.34 \\
8 & 28.2 & 1.9 & 12.5 & 5.7 & 3.05 & 0.85 & 0.50 \\
9 & 44.2 & 8.7 & 57.5 & 2.0 & 2.59 & 0.61 & 1.96 \\
10 & 63.1 & 9.9 & 37.5 & 3.3 & 3.07 & 0.72 & 1.96 \\
11 & 73.5 & 0.7 & 7.5 & 31.6 & 1.71 & 0.71 & 0.15 \\
12 & 52.2 & 2.4 & 17.5 & 8.0 & 2.98 & 0.85 & 0.65 \\
13 & 80.9 & 8.9 & 20.0 & 6.1 & 2.69 & 0.71 & 1.22 \\
14 & 76.9 & 0.7 & 5.0 & 40.5 & 2.09 & 0.87 & 0.05 \\
15 & 100.0 & 0.7 & 5.0 & 52.7 & 1.53 & 0.85 & 0.10 \\
\hline
\end{tabular}

\section{Discussion}

The data presented here show that a conservation index based on community distribution, abundance and (habitat) selectivity may be used for identifying bird habitats of special conservation concern. 'For instance, the top five communities scored by CCI represent restricted bird assemblages of species selective for particular habitats, that are not widespread on the regional scale. These communities occupy montane or alpine habitats or special riverine habitats. It is encouraging that after the CORINE database (Moss et al. 1991), Bischoff and Jongman (1993) identified a number of "potential areas of nature conservation interest" in Lombardy just in coincidence with the higher altitude levels of the alpine range and with some "stepping stones" on the Ticino and the Po rivers (by using vegetation and soil data).

The negative correlation found by comparing $\mathrm{CCI}$ with $\mathrm{ECI}$ means that, among our communities, those most widespread through the region also show the highest number of rare or endangered species. This apparently paradoxical result may in fact be due to a stochastic effect as the most widespread communities are just those most likely to include some rare species; according to Haila (1985), "the stochasticity inherent in the site selection of scarce species makes their local occurrence vary from year to year". This is also the reason why we think that CCI should be used at the community level instead of selectivity at the single species level.

On the other hand, a positive relation is well known to exist between the size of an area and the number of species detected (Arrhenius 1921; MacArthur and Wilson 1967; Connor and McCoy 1979; Bevanger 1986), also including rare species. Wiens (1989a) stresses that area affects diversity calculation through its influence on both species numbers and abundance. On this basis, it is obvious that the Shannon and Weaver diversity index is also positively correlated with geographical distribution and abundance, showing that it is affected by the number of species, irrespective of their real conservation value. As the number 
of species depends on the area, the most widespread bird communities also show the highest Shannon diversity values, but which do not necessarily identify communities of special conservation concern. This was also previously noted by Bezzel (1974) who also pointed out that, in some cases (e.g. eutrophication of inland water), "increasing species richness can be as critical as rapid decrease" $e^{\prime}$. Conversely, equitability - which is not affected by the number of species - appears a potentially better parameter for land evaluation.

As a conservation tool, CCI points out the events in which selectivity is high and geographical distribution/abundance is restricted. In most cases of this kind, we found that the habitats associated are of marginal value for human use and the conservation of the land in which the community is found may pose few social problems; conversely, low overall selectivity and wide geographical distribution involve communities containing mostly species that do not need special or expensive management for their conservation.

Finally, in the event of a wide selectivity and a wide geographical distribution, we have communities with some species that probably undergo processes of extinction and recolonization at the local level and are relatively more stable at the regional level (Burkey 1989; Thomas 1994). In the words of Rotenberry and Wiens (1980) "environmental variations obscure relationships between local populations"; conversely, local variation in bird community composition may be due to different phenomena instead of habitat selectivity, such as nesting success in the previous years, densities in the buffer zones and habitats, site fidelity and so on (O'Connor and Fuller 1985; Danielson and Stenseth 1992; Wiens et al. 1993; Andrén 1994; Thomas 1994). Anyway, the dynamics of habitat patches and species producing variation at the local scale are not evident at the landscape mosaic level, as shown by the simulation model proposed by Urban and Shugart (1986), that is - as chaos theory suggests - local disorder translates into regional or global order (Gleick 1987). The identification of bird communities at a regional scale may allow better evaluation of single habitat patches than a simple "patch by patch" description (Wiens 1989b). A very small area may contain an inadequate sample of species and individuals to determine community patterns (MacArthur 1972). In such a case, the option might be either to try to protect a very large area or, more realistically, to ensure the persistence of a large scale habitat availability through a large multiple-use area.

\section{Acknowledgements}

This work was supported by a grant of the Regione Lombardia, Assessorato Agricoltura. The first draft of the paper was greatly improved due to the comments of an anonymous referee.

\section{Appendix I}

\section{Description of the 15 community types}

Dominance ratio (in brackets) is the ratio between dominance of a given species in a community and its dominance in the entire region. 
Community 1 (group 1)

Present in 20 districts, widespread in the lowland farmland mainly in the Po valley (altitude 8-235 $\mathrm{m}$ ); characterized by habitats dominated by farmland $(60.5 \%)$, rivers $(11.2 \%)$ and wood patches $(22.0 \%)$.

Selective species: Bobwhite Colinus virginianus (7.96), Black Tern Chlidonias niger (7.96), Nightjar Caprimulgus europaeus (7.96), Fan-tailed Warbler Cisticola juncidis (7.96), Little Tern Sterna albifrons (7.79), Common Tern Sterna hirundo (7.30), Little Grebe Tachybaptus ruficollis (6.82), Melodious Warbler Hippolais polyglotta (3.77), Cetti's Warbler Cettia cetti (3.41), Golden Oriole Oriolus oriolus (2.69), Grey Heron Ardea cinerea (2.65), Skylark Alauda arvensis (2.52), Reed Warbler Acrocephalus scirpaceus (2.46), Moorhen Gallinula chloropus (2.42), Yellow Wagtail Motacilla flava (2.29), Little Egret Egretta garzetta (2.16), Pheasant Phasianus colchicus (2.05), Woodpigeon Columba palumbus (2.04), Cuckoo Cuculus canorus (1.69), Blackcap Sylvia atricapilla (1.30).

Community 2 (group 1)

Present in 17 districts, widespread all over the Po valley (altitude: $16-600 \mathrm{~m}$ ); characterized by farmland $(69.3 \%)$, urban areas $(11.6 \%)$ and wood patches (13.9\%).

Selective species: Alpine Swift Apus melba (9.97), Subalpine Warbler Sylvia cantillans (9.97), Green Sandpiper Tringa ochropus (9.97), Magpie Pica pica (3.67), Starling Sturnus vulgaris (3.24), Collared Dove Streptopelia decaocto (2.96), Pheasant (2.71), Tree Sparrow Passer montanus (2.52), Feral Pigeon Columba livia domestica (2.06), Italian Sparrow Passer domesticus italiae (1.04).

\section{Community 3 (group 1)}

Present in 12 districts in the south-western part of the region, together with the main rivers (altitude: $49-680 \mathrm{~m}$ ); characterized by farmland $(64.8 \%$ ), with more extensive areas of wood patches $(15.2 \%)$, woodland $(6.2 \%)$ and urban areas (7.8\%).

Selective species: Red-footed Falcon Falco vespertinus (15.09), Marsh Harrier Circus aeruginosus (15.09), Reed Bunting Emberiza schloeniclus (10.06), Wood Warbler Phylloscopus sibilatrix (7.54), Mallard Anas platyrhynchos (6.38), Hooded Crow Corvus corone cornix (5.83), Marsh Warbler Acrocephalus palustris (5.75), Grey Heron (5.71), Moorhen (5.58), Little Egret (5.11), Purple Heron Ardea purpurea (4.64), Night Heron Nycticorax nycticorax (3.66).

Community 4 (group 1)

Present in 25 districts, mainly in the Po valley but also in prealpine or alpine areas, usually at low altitudes (11-1000 $\mathrm{m})$; characterized by farmland $(62.7 \%)$ and urban areas $(13.6 \%)$.

Selective species: Coot Fulica atra (5.02), Swallow Hirundo rustica (3.80), Whitethroat Sylvia communis (2.97), House Martin Delichon urbica (2.44), Yellow Wagtail (1.25).

\section{Community 5 (group 2)}

Present in 7 district, on prealpine and appennine hills (altitude: 235-1350 m); characterized by woodland $(76.6 \%)$ and by comparatively small farmland areas (14.6\%). 
Selective species: Common Sandpiper Actitis hypoleucos (49.98), Cirl Bunting Emberiza cirlus (29.99), Nuthatch Sitta europaea (19.22), Garden Warbler Sylvia borin (11.99), Marsh Tit Parus palustris (11.11), Robin Erithacus rubecula (10.14), Corn Bunting Miliaria calandra (9.52), Green Woodpecker Picus viridis (7.40), Jay Garrulus glandarius (7.14), Blue Tit Parus caeruleus (5.81), Chiffchaff Phylloscopus collybita (5.36), Great Tit Parus major (4.35), Blackcap (3.08).

Community 6 (group 2)

Present in 18 districts, mainly outside the Po valley, with higher densities at middle altitudes $(10-1120 \mathrm{~m})$; variable habitat characteristics, with woodland $(35.1 \%)$, wood patches $(17.8 \%)$ and comparatively little farmland (25.7\%).

Selective species: Reed Warbler (16.6), Orphean Warbler Sylvia hortensis (16.6), Mute Swan Cygnus olor (12.45), Raven Corvus corax (11.07), Hoopoe Upupa epops (8.30), Yellowhammer Emberiza citrinella (6.23), Melodious Warbler (5.24), Longtailed Tit Aegithalos, caudatus (5.19), Great-spotted Woodpecker Picoides major (4.74), Marsh Tit (4.61), Nuthatch (3.83), Great Reed Warbler Acrocephalus arundinaceus (3.69), Green Woodpecker (3.69), Blue Tit (3.09), Great Tit (3.02), Blackcap (2.73).

\section{Community 7 (group 2)}

Present in 26 districts, everywhere except at the highest altitudes (8-930 m); habitat dominated by urban areas $(25.6 \%)$, with an important presence of farmland $(51.4 \%)$. It is the main community of all large towns (Milano, Varese, etc.). Selective species: Short-toed Lark Calandrella brachydactyla (5.82), Italian Sparrow (2.34), Collared Dove (1.87), Serin Serinus serinus (1.79), Spotted Flycatcher Muscicapa striata (1.78), Night Heron (1.54).

Community 8 (group 2)

Present in five districts (altitude: $70-770 \mathrm{~m}$ ) with farmland $(49.0 \%)$, woodland (13.1\%) and wood patches (19.3\%).

Selective species: Greenfinch Carduelis chloris (11.50), Wryneck Jynx torquilla (9.70), Red-backed Shrike Lanius collurio (6.91), Great-spotted Woodpecker (6.76), Turtle Dove Streptopelia turtur (1.24), Garden Warbler (1.22).

\section{Community 9 (group 2)}

Present in 23 districts (altitude: 8-1212 m); habitat characterized by a predominance of farmland $(42.9 \%)$.

Selective species: Jackdaw Corvus monedula (6.09), Herring Gull Larus cachinnans (6.09), Swift Apus apus (4.98), Crested Lark Galerida cristata (4.35), Buzzard Buteo buteo (3.26), Little Ringed Plover Charadrius dubius (3.26), Black Kite Milvus migrans (2.86), Night Heron (1.56), Turtle Dove (1.24), Garden Warbler (1.22).

\section{Community 10 (group 3)}

Present in 15 districts, in the montane areas (Alps, Pre-Alps, Appennines; altitude: $196-1400 \mathrm{~m})$; characterized by extensive woodland $(55.7 \%)$, wood patches (7.8\%) and some farmland (24.8\%).

Selective species: Red-legged Partridge Alectoris rufa (14.25), Bonelli's Warbler Phylloscopus bonelli (9.86), Firecrest Regulus ignicapillus (9.50), Honey Buzzard Pernis apivorus (9.50), Crag Martin Ptynoprogne rupestris (7.12), Corn Bunting (6.78), Chaffinch Fringilla coelebs (3.90), Robin (3.70), Jay (3.66), Blue Tit (3.31), 
Wren Troglodytes troglodytes (3.26), Serin (3.26), Cuckoo (2.68), Blackcap (2.67), Great Tit (2.45).

\section{Community 11 (group 3)}

Present in three districts, in high montane areas (altitude: 1350-1800 m); characterized by hagh values of woodland $(52.5 \%)$ and heathland $(47.5 \%)$.

Selective species: Alpine Chough Pyrrocorax graculus (356.63), Lesser Whitethroat Sylvia curruca (144.65), Bullfinch Pyrrhula pyrrhula (44.20), Tree pipit Anthus trivialis (33.85), Kestrel Falco tinnunculus (33.15).

\section{Community 12 (group 3)}

Present in seven districts (altitude: 910-1900 m), in montane areas with extensive woodland $(68.0 \%)$, heathland $(14.2 \%)$ and rocks $(9.9 \%)$.

Selective species: Rock Thrush Monticola saxatilis (79.56), Peregrine Falcon Falco peregrinus (79.56), Alpine Accentor Prunella collaris (63.64), Rock Bunting Emberiza cia (53.04), Crossbill Loxia curvirostra (39.78), Dunnock Prunella modularis (38.05), Treecreeper Certhia familiaris (26.31), Chiffchaff (18.43), Song Thrush Turdus philomelos (17.68), Mistle Thrush Turdus viscivorus (17.68), Redpoll Carduelis flammea (16.75), Crested Tit Parus cristatus (11.93), Robin (4.88), Coal Tit Parus ater (4.23).

\section{Community 13 (group 3)}

Present in eight districts, in montane areas only in the Alps (altitude: 500$2050 \mathrm{~m}$ ); characterized by extensive woodland $(68.9 \%)$ and heathland $(12.6 \%)$. Selective species: Fieldfare Turdus pilaris (21.44), Hazel Hen Bonasa bonasia (21.44), Citril Finch Serinus citrinella (21.44), Nutcracker Nucifraga caryocatactes (18.76), Willow Tit Parus montanus (17.71), Ring Ouzel Turdus torquatus (16.08), Coal Tit (15.51), Treecreeper (14.29), Goldcrest Regulus regulus (14.10), Crested Tit (13.94), Whinchat Saxicola rubetra (13.87), Carrion Crow Corvus corone corone (12.25), Bullfinch (11.91), Dunnock (11.19), Redpoll (10.72), Wren (6.90), Song Thrush (5.96), Tree Pipit (5.93), Robin (5.26), Chiffchaff (4.85), Chaffinch (4.56).

\section{Community 14 (group 3)}

Present in two districts in montane areas (only in the Alps; altitude: 1932$2050 \mathrm{~m})$; characterized by woodland $(23.8 \%)$, wood patches $(19.0 \%)$, heathland (30.0\%) and rocks (25.0\%).

Selective species: Lesser Whitethroat (272.6), Redpoll (131.52), Ring Ouzel (124.94), Alpine Accentor (99.95), Buzzard (71.40), Tree Pipit (21.27), Wren $(15 \cdot 50)$.

\section{Community 15 (group 3)}

Present in two districts in montane areas (only in the Alps; altitude: 2230$2245 \mathrm{~m})$; only associated with alpine heathland $(52.9 \%)$, rocks $(44.6 \%)$ and mountain streams $(2.6 \%)$.

Selective species: Water Pipit Anthus spinoletta (512.92), Snow Finch Montifringilla nivalis (512.92), Wheatear Oenanthe oenanthe (455.93), Black Redstart Phoenicurus ochruros (123.10), Whinchat (120.69), Mistle Thrush (113.98). 


\section{References}

Andrén, H. (1994) Effects of habitat fragmentation on birds and mammals in landscapes with different proportions of suitable habitat: a review. Oikos 71: 355-366.

Arrhenius, O. (1921). Species and area. J. Ecol. 9: 95-99.

Bezzel, E. (1974) Vogelbestandsaufnamen in der Landschaftsplanung. Verh. Ges. Ekol. (Erlangen 1974), 103-112.

Bevanger, K. (1986) Number of bird species used for selection of protected areas. Fauna Norvegica Ser. C, Cinclus 10: 45-52.

Bischoff, N. T. and Jongman, R. H. G. (1993) Development of rural areas in Europe: the claim for nature. Preliminary and background studies $\left(V_{79}\right)$, Netherlands Scientific Council for Government Policy.

Blana, H. (1980) Rasterkartierung und Bestandsdichteerfassung von Brutvögeln als Grundlage für die Landschaftsplanung - ein Vergleich beider Methoden im selben Untersuchungsgebeit. Pp. 32-54 in H.Oelke, ed. Proceedings of the 6th International Conference on Bird Census Work, Gottingen, 1979

Blondel, J., Ferry, C. and Forchot, B. (1981) Point counts with unlimited distance. Stud. Avian Biol. 6: 414-420.

Burkey, T. V. (1989) Extinction in nature reserves: the effect of fragmentation and the importance of migration between reserve fragments. Oikos 55: 75-81.

Connor, E. F. and McCoy, E. D. (1979) The statistics and biology of the species-area relationship. Am. Nat. 113: 791-833.

Danielson, B. J. and Stenseth, N. C. (1992) The ecological and evolutionary implications of recruitment for competitively structured communities. Oikos 65: 34-44.

Fiedler, P. L. and Ahouse, J. J. (1992) Hierarchies of cause: toward an understanding of rarity in vascular plant species. Pp. $23-47$ in P. L. Fiedler and K. J. Jain, eds. Conservation biology: the theory and practice of nature conservation, preservation and management. New York: Chapman and Hall.

Fornasari, L. and Massa, R. (1990) Bird study and landscape planning on a large area. Pp. 203-215 in K. Stastný and V. Bejcek, eds. Bird census and atlas studies. Prague: Proceedings of XI International Conference on Bird Census and Atlas Work.

Fornasari, L., Bottoni, L. and Massa, R. (1992) Atlante degli uccelli svernanti in Lombardia. Milano: Regione Lombardia e Università degli Studi di Milano.

Fornasari, L., Bottoni, L., and Massa, R. (1995). The second generation breeding bird atlas in Lombardy. Pp. 549-560 in E. J. M. Hagemeijer and T. J. Verstrael, eds. Bird numbers 1992: distribution, monitoring and ecological aspects (Proceedings of 12th International Conference of IBCC and EOAC). Noordwijkerhout: Sovon.

Franklin, J. F. (1993) Preserving biodiversity: species, ecosystems, or landscapes? Ecol Appl. 3: 202-205.

Fuller, R. and Langslow, D. R. (1986) Ornithological evaluation for wildlife conservation. Pp.247-269 in M. B Usher, ed. Wildlife conservation evaluation. London: Chapman and Hall.

Gaston, K. J. and Lawton, H. (1990) Effects of scale and habitat on the relationship between regional distribution and local abundance. Oikos 58: 329-335.

Gauch, H. G. (1982) Multivariate analysis in community ecology. Cambridge: Cambridge University Press.

Gleick, J. (1987) Chaos: making a new science. New York: Viking.

Graber, J. V. and Graber, R. R. (1976) Environmental evaluation using birds and their habitats. Ill. Nat. Hist. Surv., Biol. Notes 97.

Grzybowsky, J. A. (1982) Population structure in grassland bird communities during winter. Condor 84: 137-152. 
Haila, Y. (1985) Birds as a tool in reserve planning. Ornis Fenn. 62: 96-10o.

Hayek, L. C. (1994) Analysis of amphibian biodiversity data. Pp. 207-270 in W. R. Heyer, M. A. Donnelly, R. W. McDiarmid, L. C. Hayek and M. S. Foster, eds. Measuring and monitoring biological diversity: standard methods for amphibians. Washington, D.C.: Smithsonian Institution Press.

ICBP (1992) Putting biodiversity on the map: priority areas for global conservation. Cambridge, U.K.: International Council for Bird Preservation.

James, F. C. and Rathbun, S. (1981) Rarefaction, relative abundance, and diversity of avian communities. Auk 98: 785-80o.

Jarvinen, O. (1982) Studies in island biogeography and their relevance for fauna conservation and management. Pp. 21-24 in B. Petterson, ed. Current problems in fauna conservation. Uppsala:Sverig Lantbruksuniversitet Institut Wildlife Ecology.

Jarvinen, $\mathrm{O}$. (1985) Conservation indices in land use planning: dim prospects for a panacea. Ornis Fenn. 62: 101-106.

Jarvinen, $O$. and Rauta (1982) Selection of conservation areas based on species composition and abundance. Pp. 21-24 in B. Petterson, ed. Current problems in fauna conservation. Uppsala: Sverig Lantbruksuniversitet Institut Wildlife Ecology.

Lance, G. N. and Williams, W. T. (1967) A general theory of classificatory sorting strategies. I. Hierarchical systems. Computer J. 9: 373-380.

Lebreton, J. D. and Yoccoz, N. (1987) Multivariate analysis of bird count data. Acta Oecologica Oecol. Gen. 2: 125-144.

MacArthur, R. H. (1971) Patterns of terrestrial bird communities. Pp. 189-221 in D. S. Farner and J. R King, eds. Avian biology. New York: Academic Press.

MacArthur, R. H. (1972) Geographical ecology. New York: Harper and Row.

MacArthur, R. H. and MacArthur, J. W. (1961) On bird species diversity. Ecology 42: 594-598.

MacArthur, R. H. and Wilson, E. O. (1967) The theory of island biogeography. Princeton: Princeton University Press.

Margules, C. R. and Usher, M. B. (1981) Criteria used in assessing wildlife conservation potential: a review. Biol. Conserv. 21: 79-109.

Massa, R. (1993) An approach to a second generation of breeding bird atlas. Ann. Mus. R. Afr. Cent. (Zool.) 268: 361-365.

Massa, R. and Fedrigo, A. (1989) A new approach for a winter bird atlas by means of point counts. Ann. Zool. Fenn. 26: 207-212.

Massa, R., Fedrigo, A., Fornasari, L., Bottoni, L. and Vigorita, V. (1990) A random sampling design approach for winter atlas work. Pp. 137-147 in K. Stastný and V. Bejcek, eds. Bird census and atlas studies. Prague: Proceedings of the XI International Conference on Bird Census and Atlas Work.

May, R. M. (1976) Theoretical ecology. Principles and applications. Philadelphia: W. B. Saunders.

Moss, D., Wyatt, B., Cornaert, M. H. and Roekaerts, M. (1991) CORINE Biotopes: the design, compilation and use of an inventory of sites of major importance for nature conservation in the European Community. Luxembourg: Office for Official Publications of the European Community.

Noss, R. F. (1983) A regional landscape approach to mantain diversity. BioScience 33: $700-706$.

Novotny, V. (1991) Effect of habitat persistence on the relationship between geographic distribution and local abundance. Oikos 61: 431-433.

O'Connor, R. J. and Fuller, R. J. (1985) Bird population responses to habitat. Pp.197211 in K. Taylor, R. J. Fuller and P. C. Lack, eds. Bird census and atlas studies. Tring, Herts, U.K.: British Trust for Ornithology.

Opdam, P., and Retel Helmrich, V. (1984) Vogelgemeenschappen van heide en hoogveen: een typologische beschrijving. Limosa 57: 47-63. 
Petit, L. J., Petit, D. R. and Thomas, E. M. (1995) Landscape-level management of migratory birds: looking past the trees to see the forest. Wildl. Soc. Bull. 23: 420-429.

Pielou, E. C. (1969) An introduction to mathematical ecology. New York: Wiley.

Prendergast, J. R., Quinn, R. M., Lawton, J. H., Eversham, B. C. and Gibbons, D. W. (1993) Rare species, the coincidence of diversity hotspots and conservation strategies. Nature 365: 335-337.

Probst, J. R. and Crow, T. R. (1991) Integrating biological diversity and resource management. J. Forestry 89: 12-17.

Rotenberry, J. T. and Wiens, J. A. (1978) Nongame bird communities in northwestern rangelands. Pp. 32-46 in R. M. De Graaf, ed. Proceedings of the workshop of nongame bird habitat management in coniferous forests of the Western United States. USDA Forest Service General Technical Report PNW-64. Portland, Oregon: Pacific Northwest Forest and Range Experiment Station.

Rotenberry, J. T. and Wiens, J. A. (1980) Habitat structure, patchiness and avian communities in north american steppe vegetation: a multivariate analysis. Ecology 61: 12281250.

Routledge, R. D. (1980) Bias in estimating the diversity of large, uncensused communities. Ecology 61: 276-281.

Solonen, T. (1985) Agriculture and birdlife in Finland. A review. Ornis Fenn. 62: 47-55.

Southwood, T. R. E. (1978) Ecological methods, 2nd edn. London: Chapman and Hall.

Svensson, S. (1977) Land use planning and bird census work with particular reference to the application of the point sampling method. Polish Ecol. Stud. 3: 99-117.

Thomas, C. D. (1994) Extinction, colonization, and metapopulations: environmental tracking by rare species. Consero. Biol. 8: $373-378$.

Tucker, G. M. and Heath, M. F. (1994) Birds in Europe: their conservation status. Cambridge, U.K.: BirdLife International (BirdLife Conservation Series 3).

Urban, D. L. and Shugart, H. H. (1986) Avian demography in mosaic landscape: modelling paradigm and preliminary result. Pp. 273-279 in J. Verner, M. L. Morrison and C. J. Ralph, eds. Wildlife 2000, modelling habitat relationships of terrestrial vertebrates. Madison: University of Wisconsin Press.

van der Ploeg, S. W. F. and Vlijm, L. (1978) Ecological evaluation, nature conservation and land use planning with particular reference to the methods used in The Netherlands. Biol. Conserv.14: 197-221.

Wiens, J. A. (1989a) The ecology of bird communities, 1. Foundations and patterns. Cambridge, U.K.: Cambridge University Press.

Wiens, J. A. (1989b) The ecology of bird communities, 2. Process and variation. Cambridge, U.K.: Cambridge University Press.

Wiens, J. A., Addicott, J. F., Case, T. J. and Diamond, J. (1986) Overview: the importance of spatial and temporal scale in ecological investigations. Pp. 145-153 in J. Diamond and T. J. Case, eds. Community ecology. New York: Harper and Row.

Wiens, J. A., Stenseth, N. C., Van Horne, B. and Ims, R. A. (1993) Ecological mechanisms and landscape ecology. Oikos 66: 369-380.

\section{LORENZO FORNASARI, ELISABETTA DE CARLI, LUCIANA BOTTONI and RENATO MASSA}

Dipartimento di Scienze dell'Ambiente e del Territorio, Via L. Emanueli 15, 20126 Milano, Italy 